\title{
DE PESCADORES ARTESANAIS A PISCICULTORES: A MUDANÇA NOS MEIOS DE VIDA ENTRE OS PESCADORES ATINGIDOS PELA CONSTRUÇÃO DA USINA HIDRELÉTRICA DO FUNIL
}

\author{
Natan Ferreira de Carvalho ${ }^{1}$ \\ Marcelo Leles Romarco de Oliveira \\ Bruno Costa da Fonseca ${ }^{3}$
}

\begin{abstract}
RESUMO
O presente artigo tem como objetivo analisar a mudança nos meios de vida dos pescadores atingidos pela construção da UHE Funil, que afetou diretamente as comunidades de Macaia, Ponte do Funil e Pedra Negra, localizadas na região do Campo das Vertentes, estado de Minas Gerais. A partir da análise dos documentos referentes ao processo de licenciamento ambiental do empreendimento, da realização de entrevistas e de trabalho campo, procuramos analisar os recursos e estratégias de vida acionadas por esses pescadores antes e depois da construção da usina, buscando entender a transformação da identidade destes pescadores a partir da substituição das atividades de pesca artesanal pela piscicultura. Como principais resultados ressalta-se que antes da construção do empreendimento estes atingidos tinham a pesca como seu principal meio de vida, a partir do enchimento do lago eles deixam de ser pescadores para se transformarem em produtores de peixe, fato que, por si só, não foi capaz de garantir a reprodução socioeconômica e cultural dos mesmos.
\end{abstract}

Palavras-chave: meios de vida, pesca artesanal, piscicultura.

\section{ARTISANAL FISHERMEN TO FISH FARMERS: THE CHANGES IN THE LIVELIHOODS OF FISHERMEN AFFECTED BY THE CONSTRUCTION OF THE HYDROELETRIC PLANT OF FUNIL}

\begin{abstract}
This paper aims to analyze the change in the livelihoods of fishermen affected by the construction of the Funil Hydroelectric Power Plant, which directly affected Ponte do Funil and Pedra Negra and Macaia communities, located in the Campo das Vertentes region of the state of Minas Gerais. Based on the analysis of the documents related to the environmental licensing process of the enterprise, interviews and fieldwork, we aimed to analyze the resources and life strategies

\footnotetext{
${ }^{1}$ Doutorando em Desenvolvimento Rural pela Universidade Federal do Rio Grande do Sul (PGDR/UFRGS).

2 Doutor em Ciências Sociais em Desenvolvimento, Agricultura e Sociedade pela Universidade Federal Rural do Rio de Janeiro (CPDA/UFRRJ); Professor do Programa de Pós-Graduação em Extensão Rural do Departamento de Economia Rural da Universidade Federal de Viçosa (UFV).

${ }^{3}$ Doutorando em Ciências Sociais em Desenvolvimento, Agricultura e Sociedade pela Universidade Federal Rural do Rio de Janeiro (CPDA/UFRRJ).
} 
triggered by these fishermen before and after the construction of the power plant, seeking to understand the transformation of these fishermen identity from the substitution of artisanal fishing activities for fish-farming. As main results is emphasized that before the construction of the entreprise these affected fishermen had fishing as their main livelihood from the lake filling they are no longer fishermen to turn into fish producers, a fact which by itself, it was not able to ensure the socioeconomic and cultural reproduction of the same.

Keywords: artisanal fishing, fish farming, livelihoods.

\section{INTRODUÇÃO}

O barramento do Rio Grande para a formação do reservatório da Usina Hidrelétrica do Funil (UHE) - uma parceria entre a Companhia Vale do Rio Doce (51\% de participação) e a Companhia Energética de Minas Gerais (49\% de participação) - no ano de 2002, provocou a inundação de uma área de aproximadamente $34,71 \mathrm{~km}^{2}$, atingindo parte dos municípios de Lavras, Perdões, Bom Sucesso, ljaci, Itumirim e Ibituruna, entre as regiões do Campo das Vertentes e Sul de Minas, no estado de Minas Gerais.

Esta área representava o local de morada de várias famílias que, ao longo dos anos utilizavam os recursos naturais e sociais na construção de seus meios de vida, que configuravam formas ou modos como esses atores viviam. Era neste local que trabalhavam, plantavam, colhiam, pescavam, rezavam, se divertiam, etc., mas que posteriormente tiveram de ser realocadas para a construção da referida usina hidrelétrica. Este acontecimento afetou diretamente as comunidades de Pedra Negra e Ponte do Funil - que ficaram quase totalmente debaixo d'água - e a comunidade de Macaia, que ficou parcialmente submersa, tendo sido realocados somente os moradores que ocupavam as faixas mais próximas da calha original do rio.

Ao comparar as diferentes formas com que esses recursos e estratégias assumiam antes e assumem agora, depois da construção da usina, buscamos entender a forma com que se dá o processo de reprodução social dos mesmos, particularmente através do trabalho, da utilização de recursos naturais disponíveis e outras formas de obtenção de renda. Neste sentido, o presente artigo tem como objetivo analisar o processo de mudança nos meios de vida dos pescadores atingidos pela construção da UHE Funil, tendo como foco as diferentes combinações de recursos que esses pescadores utilizavam como estratégias para construírem suas formas de vida, buscando analisar também o papel que o programa de compensação, na área socioeconômica, proposto pelo consórcio empreendedor, assume dentro desta problemática.

É importante destacar que a escolha por estudar especificamente os expescadores do Funil $^{4}$ se deu pelo fato de que estes não apenas viviam nas margens do Rio Grande, mas dependiam diretamente deste, que se constituía como o seu local de trabalho por excelência. Nesse aspecto, a chegada da UHE Funil transformou drasticamente a realidade destes pescadores, obrigando-os a reconstituírem suas identidades em um novo local.

\footnotetext{
${ }^{4}$ Escolhemos utilizar a expressão ex-pescadores pelo fato de que, como veremos ao longo deste artigo, os mesmos deixaram de exercer a pesca artesanal e passaram a ser piscicultores, produtores de peixe.
} 


\section{MÉTODOS}

Partindo da ideia de que as discussões sobre métodos e técnicas de pesquisa somente adquirem relevância no contexto de orientações teóricas específicas e com base em problemas concretos, para interpretar os efeitos sociais da construção da UHE Funil por meio da análise das transformações nos meios de vida acionados pelos pescadores atingidos, utilizou-se, para esta pesquisa, os métodos qualitativos e a escrita etnográfica, ambos legatários de uma tradição de estudos antropológicos.

Entende-se que o conceito de meios de vida vem sendo particularmente utilizado para analisar processos de desenvolvimento em países do terceiro mundo, principalmente no continente Africano (ELLIS, 2000), por meio da descrição e análise dos diferentes modos com que as pessoas constroem suas formas de vida. O termo, comumente utilizado em relação aos processos do mundo rural, geralmente aborda as diferentes combinações de recursos que a população rural possa utilizar localmente como estratégias para construir suas formas de reprodução social através do trabalho (agrícola e não-agrícola), redes sociais acionadas, conhecimento, tecnologia, emprego, utilização de recursos naturais e outras formas de obtenção de renda (HENBICK, 2007).

Dito isso, nesta pesquisa utilizou-se métodos desenvolvidos por antropólogos pesquisadores da "Escola de Manchester", da Inglaterra, que procuraram adequar o arcabouço antropológico - baseado na coleta de dados microscópicos e detalhados - para a análise de processos de mudança social dentro das chamadas sociedades contemporâneas (FELDMAN-BIANCO, 1987). Mais especificamente, procuramos desenvolver a proposta de estudo de caso detalhado por meio da "análise situacional" (VAN VELSEN, 1987) do processo de mudança social vivido por estas famílias a partir da construção da usina.

Levando-se em conta o fato de que os meios de vida não são estáticos, mas se inserem em contextos de heterogeneidade social e se transformam ao longo da vida dos atores que buscam responder aos diversos fatores pelos quais estão expostos e que alteram seus meios de vida (como as mudanças provocadas por alterações climáticas- secas, enchentes, etc.-, a perda de rendimentos por qualquer outra razão ou até mesmo por mudanças estruturais como as provocadas pela construção de uma UHE, como é o caso aqui analisado), e tendo em vista a metodologia adotada, a pesquisa teve como foco o indivíduo em relações sociais concretas, mas sem perder de vista as implicações entre processos sociais em múltiplas escalas (local, regional, global).

Com isso, fez-se necessário a realização de uma pesquisa de campo mais intensa numa unidade de análise menor, para que se pudesse compreender melhor o comportamento concreto e a prática cotidiana de um número restrito de indivíduos (VAN VELSEN, 1987). Como argumenta Gomes (2007), a análise e a interpretação dentro de uma perspectiva de pesquisa qualitativa não têm como finalidade contar opiniões ou pessoas; seu foco principal é a exploração do conjunto de opiniões e representações sobre o tema a ser estudado.

Nesse sentido, durante os meses de agosto e setembro do ano de 2010 e em janeiro de 2012, foi realizado um trabalho de campo na comunidade do Funil composta por quarenta famílias que tinham a pesca e o turismo como as principais fontes de renda ${ }^{5}$. Destaca-se que nesse trabalho de campo, foram utilizadas

\footnotetext{
${ }^{5}$ Além da pesca, as atividades agropecuárias desenvolvidas nas propriedades referiam-se basicamente ao cultivo de produtos alimentares voltados para o autoconsumo.
} 
entrevistas semiestruturadas como suporte para o entendimento das questões propostas. Como o foco da pesquisa recaiu sobre os pescadores atingidos, os critérios de escolha das famílias entrevistadas foi o fato de exercerem a atividade da pesca antes da formação do lago da UHE Funil e de participarem da Cooperativa de Pesca da Ponte do Funil (COOPERFUNIL) que, fazendo parte do Programa de Reativação Econômica proposto pelo consórcio empreendedor, constituía-se como a principal forma de compensar o trabalho da pesca exercida na região. Todos os pescadores que participavam ativamente da cooperativa na época da pesquisa, doze no total, foram entrevistados ${ }^{6}$.

Para além das entrevistas, buscou-se estabelecer uma aproximação e uma interação direta com a comunidade, vivenciando parcialmente suas experiências diárias, travando contatos e diálogos para tentar compreender as atividades e interações da vida cotidiana dos pescadores atingidos. De maneira complementar, foi realizada também uma análise dos documentos referentes ao processo de concessão do licenciamento ambiental da Hidrelétrica do Funil. Para isto consultouse arquivos do Sistema Estadual de Meio Ambiente - SISEMA e da Superintendência Regional de Meio Ambiente e Desenvolvimento Sustentável SUPRAM - do Sul de Minas. Este material consultado possibilitou um entendimento do processo de licenciamento ambiental do referido empreendimento.

Realizou-se também uma entrevista com um técnico da SUPRAM e com uma socióloga da empresa de consultoria ambiental ${ }^{7}$, contratada pelo consórcio empreendedor para fazer o acompanhamento dos Programas de Reativação Econômica na Comunidade do Funil. Essas entrevistas permitiram compreender melhor como foram os procedimentos e as dificuldades de implantação da usina hidrelétrica.

\section{RESULTADOS E DISCUSSÃO}

\subsection{O PESCADOR ARTESANAL E O PROCESSO DE EXTINÇÃO DA CATEGORIA}

De acordo com a lei $n^{\circ} 11.959$, de 29 de junho de 2009, que dispõe sobre a Política Nacional de Desenvolvimento Sustentável da Aquicultura e da Pesca, no seu Capítulo IV, Seção I, Art. $8^{\circ}$, a pesca é classificada como:

\section{Comercial:}

a) Artesanal: quando praticada diretamente por pescador profissional, de forma autônoma ou em regime de economia familiar, com meios de produção próprios ou mediante contrato de parceria, desembarcado, podendo utilizar embarcações de pequeno porte;

b) Industrial: quando praticada por pessoa física ou jurídica e envolver pescadores profissionais, empregados ou em regimes de parceria por cotas-partes, utilizando embarcações de pequeno, médio ou grande porte, com finalidade comercial.

\footnotetext{
${ }^{6}$ Cabe destacar aqui que nem todas as famílias que exerciam a atividade da pesca antes da construção da usina participaram da construção da COOPERFUNIL. Muitos não se adaptaram ao novo local de moradia e aos novos meios de vida que se tornaram possíveis depois da construção da hidrelétrica e acabaram se mudando pra diferentes regiões no Estado de Minas Gerais. Durante o trabalho de campo não foi possível entrevistar essas famílias, portanto, a pesquisa centrou-se naquelas que continuaram morando na comunidade realocada e que participaram em algum momento da cooperativa que foi criada pelo consórcio empreendedor como principal forma de compensar a pesca realizada, até então, na região.

${ }^{7}$ Empresa Práxis Projetos e Consultoria, sede em Belo Horizonte.
} 
II. Não Comercial:

a) Científica: quando praticada por pessoa física ou jurídica, com a finalidade de pesquisa científica;

b) Amadora: quando praticada por brasileiro ou estrangeiro, com equipamentos ou petrechos previstos em legislação específica, tendo por finalidade o lazer ou o desporto;

c) De subsistência: quando praticada com fins de consumo doméstico ou escambo sem fins de lucro e utilizando petrechos previstos em legislação específica.

As leis podem ser compreendidas como importantes mecanismos de regulação ou até mesmo de modelagem das estratégias de sobrevivência, ou, em outras palavras, "[...] é um elemento constituinte dos meios de vida das pessoas, no sentido de que, ao "regular" as condutas, estabelece o que pode e o que não pode ser feito, impõe mudanças de atitude e consequências pela não adequação aos padrões exigidos" (PEREIRA; BOTELHO, 2015, p. 102). Para este estudo, portanto, conforme a lei $n^{\circ} 11.959$, o tipo de pesca que será discutido refere-se às práticas comerciais e as que dizem respeito à pesca artesanal, bem como as de prática não comercial de "subsistência". Cabe ressaltar, que apesar da lei supracitada separar os pescadores artesanais dos pescadores de "subsistência", na prática as duas situações coexistem e não se excluem. A escala de produção pequena e a destinação do peixe - em parte para o autoconsumo e em parte para o comércio, em regime de economia familiar - também são elementos definidores da pesca profissional artesanal (DIEGUES, 2002 apud VENTURATO, 2008, p. 48).

Ao longo de todo litoral brasileiro e nas águas interiores do país, encontramos diversas pessoas e até famílias, que têm na pesca artesanal o exercício de uma atividade na qual se mesclam as condições objetivas de sua reprodução, como o acesso à alimentação e renda, com condições subjetivas, como o conhecimento tradicional sobre 0 meio natural e o trabalho fortemente condicionado por dinâmicas ambientais (PASQUOTTO; MIGUEL, 2004).

As características essenciais da pesca estão associadas à forma de aquisição do conhecimento e desenvolvimento de habilidades para o exercício da profissão, que são transmitidos pela tradição. Diegues (1995) vê a questão da tradição como parte constituinte da pesca artesanal, colocando o conhecimento tradicional como fator essencial para balizar as práticas de extração de peixes nativos de vários ecossistemas distintos como os rios, lagos e oceanos. Conforme o autor:

A questão da tradição está relacionada também ao cerne da própria pesca artesanal: o domínio do saber-fazer e do conhecer que forma o cerne da "profissão". Esta é entendia como o domínio de um conjunto de conhecimentos e técnicas que permitem ao pescador se reproduzir enquanto tal. Esse controle da "arte da pesca" se aprende com "os mais velhos" e com a experiência (DIEGUES, 1995, p. 35).

Além da questão da tradição, outro aspecto fundamental para se compreender o trabalhador da pesca é entender a relação que o pescador estabelece com o meio ambiente ao qual está inserido e a influência deste sobre o seu trabalho. Como afirma Valencio et al. (2003):

$\mathrm{O}$ ato de capturar o peixe como principal meio de sustento da família está associado tanto à aguda percepção ambiental deste trabalhador, que vivencia o cotidiano do rio e dos que 
dele dependem, quanto à sua capacidade de elaborar os meios de produção próprios a essa extração e de desenvolver técnicas corporais peculiares no manejo dos petrechos. $\mathrm{Na}$ pesca, a jornada de trabalho é descontínua, posto que o ritmo é ditado pela natureza: a hora de sair, de colocar a rede e recolhê-la, ou de jogar a tarrafa, não é desígnio direto das relações sociais, mas do comportamento dos peixes. O saber tradicional sobre os processos ecossistêmicos envolvidos na atividade é, portanto, condição sinequa non para a existência do próprio pescador. Isso faz com que este conheça as condições do rio momento a momento (VALENCIO et al., 2003, p. 273).

Essa reflexão nos faz compreender que os pescadores possuem um profundo conhecimento acerca da estrutura e dinâmica do ecossistema ao qual estão inseridos, sabem exatamente quais os tipos de ambientes propícios à vida de cada espécie de peixes existentes naquela região, conhecem 0 hábito, 0 comportamento e a classificação dos peixes, sabem manejar os instrumentos de pesca com propriedade, conseguem identificar os melhores pontos de pesca, pois, possuem domínio sobre o meio em que vivem e do qual depende a sua existência enquanto pescador (DIEGUES, 1983; 1995).

No entanto, além da perspectiva ambiental em que a atividade se realiza, há a questão do conjunto social identificável com a ocupação. Segundo Valencio et al. (2003), um dos maiores problemas relacionados aos estudos sobre a pesca profissional artesanal está na identificação do conjunto de trabalhadores que a representa, pois não se pode tomar automaticamente a categoria por aqueles que estão institucionalizados. $\mathrm{Na}$ realidade, dentro da categoria de pescadores artesanais que fazem da atividade da pesca sua principal fonte de renda, podemos encontrar dois subgrupos básicos, classificados pelos autores da seguinte maneira:

1. Aqueles que exercitam a profissão e estão devidamente cadastrados na Delegacia Federal de Agricultura $^{8}$ e/ ou nas colônias/associações de pesca, que podem mediar o registro do trabalhador nesse órgão.

2. Aqueles que não estão cadastrados nas colônias de pesca ou em quaisquer órgãos competentes, mas exercitam a atividade com regularidade e como principal fonte de renda da família. São os chamados pescadores clandestinos (VALENCIO et al., 2003, p. 274).

É importante destacar que há, também, aqueles pescadores que estão cadastrados nas colônias/associações de pesca, mas que são, na verdade, pescadores amadores, que não fazem da pesca o seu principal meio de vida e que tentam o cadastramento junto aos órgãos competentes com o intuito de usar equipamentos permitidos apenas aos pescadores profissionais e até mesmo para receber o Seguro Defeso (no valor correspondente ao de um salário mínimo) pago através do INSS na época do período de defeso ${ }^{9}$.

\footnotetext{
${ }^{8}$ Com a transformação da Secretaria Especial de Aquicultura e Pesca em Ministério da Pesca e da Aquicultura em junho de 2009 (lei 11.958), os pescadores passaram a ser cadastrados neste Ministério.

${ }^{9}$ Período em que a pesca passa a ser proibida com o intuito de garantir a reprodução dos peixes. O segurodefeso é pago somente aos pescadores profissionais devidamente cadastrados no órgão competente, porém, a fiscalização para garantir se todos os cadastrados são realmente pescadores profissionais que têm na pesca o seu principal sustento é muito difícil. Em 2004 houve um escândalo devido à proliferação de
} 
A pesca amadora, em que é exercida com fins de lazer ou desporto, também deve ser levada em consideração uma vez que, ainda que sua atividade seja permitida por lei, muitas vezes entra em conflito direto com os pescadores artesanais. Segundo Valencio (2007):

Não se pode falar da pesca profissional como captura de peixe silvestre sem reportar-se à pesca amadora, que se amplia no afã da mesma captura - pouco importa se levando os espécimes capturados consigo, para quaisquer fins, ou devolvendo-os, feridos, aos rios - e tem domínio dos mesmos territórios onde o trabalhador da pesca, na sua canoa, tem logrado obter o seu sustento (VALENCIO, 2007, p. 102).

Mendonça (2004), analisando os conflitos de territorialidade existentes entre o turismo, a pesca amadora, e a pesca profissional artesanal no Alto-Médio São Francisco aponta para a mercantilização e banalização do lugar e da população em questão. Segundo o autor:

O processo de planejamento, implantação, e operacionalização dos empreendimentos turísticos da pesca amadora estão provocando impactos sobre a fauna e a flora - em especial aquelas relacionadas aos usos múltiplos das águas -, e sobre a vida das pessoas - em especial a exclusão social gerada ao privar as pessoas do território e das relações sociais em que se baseiam a reprodução dos meios naturais e tradicionais de subsistência (MENDONÇA, 2004, p. 285).

Não podemos considerar o pescador artesanal fora do contexto em que está inserido, há diversos fatores ocorrendo na sociedade que influenciam diretamente o exercício de sua atividade. Além da concorrência com os pescadores amadores, podemos citar o domínio concentracionista da terra, com a apropriação privada de lagoas marginais e o desvio das águas fluviais, o aumento da carga de efluentes de origem industrial e doméstica jogados nos rios, e, principalmente, a construção de usinas hidrelétricas, fatores que vão minando a capacidade de reprodução e sobrevivência dos peixes e, por decorrência, minando a capacidade de reprodução da pesca, levando os pescadores profissionais a viverem situaçõeslimite $^{10}$ (VALENCIO et al., 2006).

As atividades que potencialmente têm impacto na pesca de água doce muitas vezes não têm relação direta com a captura do peixe, como é o caso dos esgotos domésticos e industriais jogados nos rios, a poluição oriunda da agroindústria, os agrotóxicos carregados aos rios pela ação da chuva, etc. Estes fatores, que parecem "invisíveis" por se apresentarem distantes da realidade dos pescadores, comprometem negativamente a qualidade da água, impactando

\footnotetext{
carteiras de pescador profissional que eram feitas sem muitos critérios e sem nenhuma fiscalização. Depois do escândalo a fiscalização passou a ser maior e os problemas parecem ter diminuído.

${ }^{10}$ Diegues (1995) observou uma situação parecida em relação ao pescador artesanal que exerce sua atividade no litoral brasileiro, segundo o autor: "Com o crescimento da pesca empresarial-capitalista, que conflitava diretamente com a pesca artesanal, somado ao uso crescente dos ecossistemas litorâneos e costeiros, para a implementação de polos químicos, petroquímicos, minero metalúrgicos, levou a poluição dos estuários, com o empobrecimento biológico dos recursos tradicionalmente capturados pela pesca artesanal. A especulação imobiliária, expulsando os pescadores artesanais de suas praias, algumas vezes de maneira violenta, contribuiu para uma desorganização social crescente e para um empobrecimento ainda maior das comunidades dos pequenos produtores" (DIEGUES, 1995, p. 56).
} 
diretamente os peixes e consequentemente os pescadores. Como afirma Venturato (2008):

\begin{abstract}
Nesse sentido, é certo afirmar que a constituição do trabalho do pescador artesanal não só é vulnerável às adversidades do ambiente natural, como também é suscetível às mudanças ocasionadas pelas práticas socioambientais de outros usuários das águas. Assim, a pesca artesanal representa uma categoria profissional e um modo de vida responsável por tecer continuidade às tradições, mas, numa heteronímia, hoje é uma categoria prestes a extinguir-se (VENTURATO, 2008. p. 53).
\end{abstract}

A apropriação dos recursos hídricos para fins de geração de energia elétrica tem contribuído decisivamente para a situação em que se encontram os pescadores artesanais atualmente. Ao transformarem o rio em lago, tornando as características ambientais desfavoráveis ao desenvolvimento de algumas espécies de peixe, ao mesmo tempo em que, objetivando o armazenamento hídrico, inviabiliza a continuidade, a jusante, do ciclo natural das enchentes que repovoariam o rio, as hidrelétricas estão potencializando o processo crescente de exclusão e pauperização do pescador artesanal (VALENCIO et al., 2006).

No entanto, é importante deixar claro que os principais problemas enfrentados pelos pescadores artesanais devido à destruição ecológica e ao esgotamento dos recursos não são problemas gerados por processos naturais, mas são determinados pelas formas sociais e pelos padrões tecnológicos de apropriação e exploração econômica da natureza (LEFF, 2001). Os conflitos provocados pelas diferentes formas de apropriação dos recursos hídricos e as disputas do território das águas e dos peixes oriundos do mesmo, estão provocando a extinção de uma categoria ocupacional e de um meio de vida particular, relacionado à pesca artesanal.

Esta realidade se torna ainda mais preocupante ao levarmos em conta a solução encontrada pelo poder público, em diversas localidades do território brasileiro, para compensar esta situação vivida pelos pescadores, qual seja o incentivo à prática da aquicultura. Processos político-institucionais em curso estão trazendo à tona o conflito - até então latente - entre a pesca profissional artesanal de água doce e a aquicultura. Esta, considerada como a solução técnica mais viável, acaba também adquirindo a imagem de sustentabilidade em contraposição a um discurso, produzido por diversas vias do Executivo e Legislativo, em níveis federal e estadual - com respaldo de parte da comunidade científica e da mídia - que responsabiliza a pesca artesanal pela escassez de peixes nos rios (VALENCIO et al., 2003). Dentro deste contexto, as falas competentes fazem surgir a seguinte ideia:

A de que a aquicultura empresarial seria uma alternativa sustentável, social, ecológica e economicamente: no âmbito do emprego e renda, quer incitar o entendimento público de que seu propósito é o de inclusão social, abrangendo aqueles que se veriam impedidos do exercício de sua ocupação por razões "ambientalmente justificáveis", os pescadores-depredadores. Sob uma perspectiva ecológica, a aquicultura, para além do papel de redentora social, seria redentora do peixe silvestre, liberto de seu uso como alimento. E sob um prisma econômico, atingiria o nível de eficácia de que a natureza sozinha não é capaz, ao produzir com ganhos de escala e ampliando o mercado, argumento último de busca de legitimidade que 
passa, ainda, pela questão da segurança alimentar (VALENCIO et al., 2003, p. 272).

No entanto, como procuraremos demonstrar em relação aos ex-pescadores do Funil, a adoção da aquicultura como solução para pesca artesanal profissional só faz concretizar um projeto modernizador do uso dos recursos hídricos em curso no Brasil, que está provocando profundas transformações nos meios de vida de diversas populações ribeirinhas, principalmente dos pescadores. Como afirma Valencio (2006):

\begin{abstract}
Pegue-se, como ilustração, uma das alternativas pacificadora que é veiculada como a resposta moderna, no nível federal $(\mathrm{SEAP})^{11}$ ao colapso pesqueiro: a aquicultura e suas variantes. Esta exige a dissolução da cosmogonia da pesca artesanal para a incorporação de um outro esquema classificatório com foco em molusco, crustáceo, espécies estranhas de peixe (não silvestres, invasoras ou introduzidas), rotinas de horário industrial para a lida com remédios e ração etc. E gera alterações na identidade coletiva provocadas pela perda das técnicas corporais relacionadas à pesca e que não cabem no manejo semi-fabril, de escala (VALENCIO, 2006, p. 8).
\end{abstract}

Para entendermos melhor esta mudança, a transformação do pescador artesanal em piscicultor, vamos tomar por base o estudo de caso feito com os Pescadores da Ponte do Funil, que viram-se obrigados a mudar os seus meios de vida não por incentivo do Governo, mas devido à implantação da Usina Hidrelétrica do Funil, onde a piscicultura foi escolhida como principal forma de compensação aos pescadores atingidos.

\title{
3.2. O (EX)PESCADOR DA PONTE DO FUNIL
}

É importante destacar que, por ser uma região de corredeira, a pesca realizada na antiga Ponte do Funil, em muitos trechos, era proibida, o que impossibilitava que os pescadores fossem institucionalizados por meio de alguma Colônia de Pesca que pudesse fazer a intermediação com o órgão do Governo à época responsável pelo cadastramento dos pescadores artesanais profissionais.

Entretanto, apesar de não estarem institucionalizados, vários destes pescadores eram sustentados pela pesca e, por isso, na ocasião, insistiam que esta era uma atividade essencial para muitas famílias e que, portanto, deveria ser compensada. Como afirma um ex-pescador ao ser questionado a respeito da construção da usina:

Ah, nois perdeu muita coisa, perdeu tudo uai. Nois vivia era da pesca lá embaixo, era uma pesca que nois não poderia pescar, mas nois vivia né, nois tinha um ganho certo, só que agora...lá nois não podia pescar só que nois vivia era disso não tinha outro serviço, o serviço era a pesca pra nos manter, manter a família né... (S., ex-pescador, setembro de 2010).

\footnotetext{
${ }^{11}$ Secretaria Especial de Aquicultura e Pesca, hoje Ministério da Pesca.
} 
O fato de a pesca ser considerada proibida naquela região fez com que o consórcio empreendedor colocasse resistência em considerar os pescadores nos projetos de compensação propostos para os atingidos. Desde o processo de licenciamento ambiental do empreendimento, o consórcio empreendedor começou a armar algumas estratégias para desmobilizar a categoria. A própria contratação de alguns pescadores para trabalhar na construção da usina acabou prejudicando uma possível mobilização dos mesmos. Como afirma outro ex-pescador:

[...] quando instalou o canteiro de obras, ai eu comecei a trabalhar direto para o consórcio, trabalhei em tudo quanto é área que você pensar, o último serviço que eu fiz pra eles foi na limpeza do reservatório que eu era fiscal, trabalhei no resgate de fauna, trabalhei tudo ai, e a gente pescava antes né, e num determinado tempo, um ano antes de começar a usina a gente já parou de pescar porque a gente já estava trabalhando bastante pra usina, e ai a pesca foi ficando meia esquecida (A., ex-pescador, setembro de 2010).

Ao ser perguntado sobre se os outros também trabalhavam na usina, o mesmo respondeu:

É, não, os outros continuavam né, a maioria, alguns que trabalhava na usina, os que não queria trabalhar na usina continuava na pesca. Mas ai começou o processo de negociação e eles sempre deixando os pescador de lado, porque lá era uma pesca predatória e eles acharam que não tinha responsabilidade nenhuma com aquilo, e eu falava com eles, olha, não é dessa forma não, e como eu trabalhava pra eles automaticamente eu tinha que ficar meio quieto né, mas só que chegou uma época que me revoltou aquilo, aí falei, não, agora eu chuto o pau da barraca, e comecei a organizar os pescador, chamava eles e falava, olha gente, nos temos que lutar porque pelo que eu estou vendo nos vamos ficar pra traz nisso ai, aí batia [o consorcio] e chamava a polícia ambiental que falava que era tudo ilegal, mas eu falava, se vocês não vier instalar a usina vamos todo mundo continuar pescando da mesma forma que sempre fizemos, eu nasci com isso ai ué, meu pai me sustentou desde criança com isso aqui, então nos temos que rever essa questão [...] (A., ex-pescador, setembro de 2010).

Inicialmente os pescadores tiveram dificuldades para se organizarem, mas a partir do momento que o ex-presidente da colônia começou a reivindicar e tomar frente no processo de negociação com o consórcio empreendedor houve uma forte mobilização por parte dos pescadores. Eles chegaram inclusive a escrever uma carta de reivindicação que foi entregue, primeiro para a Fundação Estadual do Meio Ambiente - FEAM, depois para alguns políticos da região ${ }^{12}$ e distribuída também para a população local, com o intuito de explicitar a necessidade e a luta pelo reconhecimento dos pescadores enquanto atingidos.

A essa altura a FEAM já havia exigido do consórcio empreendedor um cuidado especial para com os pescadores da Ponte do Funil, reiterando diversas vezes a necessidade de compensar a atividade de pesca praticada na região. Nesse

\footnotetext{
${ }^{12} \mathrm{Em}$ entrevista ao ex-presidente da colônia este afirmou que entregou a carta inclusive para o governador do Estado à época, Itamar Franco, quando da inauguração da Usina.
} 
sentido, com o intuito de tentar encontrar uma solução viável para a reestruturação da atividade, o consórcio empreendedor abriu para negociação e começou a fazer diversas reuniões com o grupo de pescadores. Depois de várias discussões e debates, chegou-se à conclusão de que a melhor forma de compensar a atividade pesqueira seria através da criação de uma cooperativa que passaria a ser responsável pela retomada da atividade na região.

Apesar da Cooperativa de Pesca da Ponte do Funil (COOPERFUNIL) ter se tornado o "carro chefe" dos programas de reativação econômica propostos pelo consórcio empreendedor, ela não conseguiu contemplar todas as famílias que exerciam a pesca antes da construção da usina. Como afirma o primeiro presidente da Colônia:

\begin{abstract}
Nós éramos uns 50 pescador, mas você sabe né, esse povo quer fazer cada vez menos né, faz o que a lei manda e olhe lá, faz menos ainda, ai a gente começou uns dois anos avançando na negociação, fazia reunião todo mês, toda quinzena, ai tinha pescador que foi desanimando ao longo do tempo, porque é aquela história, o cara quer resultado prático, rápido, e eles não faz justamente pra turma desanimar, ai chegou uma época que começou a criar critério, ah pra poder ganhar alguma coisa tem que participar da reunião, ai muito nêgo foi desanimando e eles foi cortando, cada vez que vinha com a lista cortava três, quatro nomes, ai chegou uma época que não teve como evitar mais, ai fechamos o grupo em doze pessoas, mas ai eles falaram que doze não era suficiente para criar uma cooperativa, ai sugeriram para inteirar com as esposas, ai inteiramos, chegou a vinte e fundamos a cooperativa. Os outros [que ficaram de fora] foi um "tendepar" danado rapaz, porque foi o seguinte, ninguém acreditava no processo, mas o dia que viu o caminhão descarregando o barco, as redes, ai falaram, uai, porque que eu não tô nisso? Uai, você não tá porque você se excluiu do processo, ai eles reclamaram, bateram em cima, imprensa foi de cima, mas já não tinha força mais, porque já tinha um grupo formado, isso ficou até uma situação ruim, eu não queria que a coisa fosse dessa forma, porque o objetivo nosso era ajudar todo mundo sabe, mas [...] (A., ex-pescador, setembro de 2010).
\end{abstract}

Inicialmente o objetivo do consórcio empreendedor era reativar a pesca artesanal e o primeiro passo dado foi fazer a carteira de pescador profissional, cadastrando os pescadores na colônia de pesca no município de Alfenas-MG ${ }^{13}$. Esta foi uma prática muito importante para os pescadores já que a vida inteira realizaram uma atividade considerada ilegal e agora, depois do enchimento da represa, passaram a ser institucionalizados e reconhecidos pelo Governo.

No entanto, apesar desta atitude ter Ihes garantido a legalidade do exercício da profissão de pescador, com o enchimento do lago, o que lhes passou a faltar não foi a carteira de pesca, mas o peixe, essencial para a sua existência. Não existe pescador sem peixe, mesmo que ele seja institucionalizado. Conforme relatos dos ex-pescadores:

[...] ai juntaram com a usina, foram lá ver o negócio de carteira, foram lá em Alfenas, ai conseguimos a carteira de pesca. Mas depois que a gente começou a pescar nós vimos que não dava

\footnotetext{
${ }^{13} \mathrm{Na}$ época ainda não havia sido criada a Colônia de Pesca no município de Lavras.
} 
peixe, que não tinha como. Não tinha peixe! Você armava ai mil metro de rede você pegava um quilo por semana de peixe, tinha semana que não pegava nem um. E outra coisa também mais séria dessa conversa nossa, eles, pra poder encher o lago rápido [...] eles encheram o lago cheio de lenha, sujo, não limparam tudo lá, deixou tudo sujo lá, ai você colocava a rede e quando ia tirar rasgava tudo (G., ex-pescador, setembro de 2010).

Montaram essa cooperativa ai pra nós, muito bem montada, tem freezer, deram rede, deram barco, deram tudo, muito bem montado, mas faltou o principal que era o peixe (N., expescador, setembro de 2010).

Além da questão da falta de peixes, como vários entrevistados relataram, e apesar do consórcio ter oferecido toda a condição, em termos de material para se pescar, a forma com que a atividade é exercida no lago é completamente diferente da maneira como ela era feita no rio, o que provocou sérios problemas de adaptação por parte dos pescadores. Como comentaram os mesmos:

É muito diferente o jeito, a própria pesca no rio é totalmente diferente da do lago, tanto é que quando a Usina foi dar equipamento, nós fomos em Alfenas comprar as redes, compramos rede de pescar em rio, chegamos aqui e as redes ficaram tudo ai, perdida, jogada fora, não funcionou, as redes no rio tem que ter bóia, chumbo, tem que ser adaptada, aqui não, a gente punha aquelas boinha de isopor, amarrava pedra, foi aquela loucura, e a usina nem pra chamar um cara que já entende disso pra dar uma consultoria, deixou a gente "a Deus dará", ficamos com uma tonelada de rede ai sem saber o que fazer e não pegava um peixe, foi muito difícil (A., ex-pescador, setembro de 2010).

[...] até você se adequar ao lago foi difícil, porque aqui você pesca mais é de rede, e o quê que acontece, aqui nos estamos em uma profundidade de 40 metros, e o peixe de escama ele pega o fio d'água aqui e vai embora, a tendência dele é ir pro rio das Mortes, Capivari, o que fica mais aqui é uma Curimba que é acostumada a água parada, mudou muito, os peixes, a maneira de pescar, foi uma mudança meio brusca [...] $(F .$, expescador, setembro de 2010).

Essa situação nos mostra que o trabalho do pescador não é replicável em outros territórios. Na atividade da pesca, lugar e trabalho estão impreterivelmente imbricados, portanto, quando se muda o lugar da pesca, muda-se também o trabalho nele exercido. A forma de produção na pesca varia bastante, encontrando desde pescadores que jogam suas linhas e redes em praias ou margens dos rios, até grandes embarcações que contam com todo um aparato tecnológico de pesca. $\mathrm{Na}$ Ponte do Funil eram utilizadas técnicas artesanais de captura, ou seja, tecnologias simples e de baixo custo como: redes de espera, tarrafas e anzóis. A utilização destes petrechos de pesca em específico revelam a intenção e o controle dos pescadores sobre algumas espécies de interesse, demonstrando suas habilidades e seus conhecimentos sobre o comportamento das espécies (VALENCIO et al., 2006). 
O uso destes tipos de petrechos também indica a existência de condições ambientais favoráveis à reprodução dos peixes maiores e de grande importância econômica, como é o caso do Dourado, peixe que era abundante na antiga Ponte do Funil e que depois da construção da barragem, que cortou o seu ciclo natural de reprodução, vem se acabando paulatinamente ${ }^{14}$. Como lamenta um ex-pescador:

[...] daqui um tempo não vai ter mais Dourado, que é o rei do rio nosso aqui, é o peixe que todo mundo vinha do Brasil, de qualquer parte do Brasil, até do Paraguai, Uruguai, eu já vi gente que vinha aqui pescar atrás do Dourado, porque tinha muito mesmo, e agora vai acabar [...] (G., ex-pescador, setembro de 2010).

Uma particularidade da pesca na Ponte do Funil é que ela também era realizada em pé, sobre as pedras, no meio das corredeiras, de onde os pescadores jogavam suas tarrafas. Esta prática, embora ilegal, seguia um conjunto bastante específico de regras comunitariamente estabelecidas. Como afirma um ex-pescador:

Antes era assim, cada qual tinha um horário pra pescar, de quarenta em quarenta minutos um pescava né, era dividido, então o peixe que fosse pego no tempo da minha pescaria era meu, ai então eu dividia com o tarrafeiro, sabe, e os outros não, cada qual ficava com o seu [...] tinha um tempo determinado, 40 em 40 minutos ou de hora em hora, depende do volume de peixe, ai depois trocava de pescador, era outro, então quem chegasse primeiro no local de pesca era o primeiro, o segundo era o segundo, por ordem de chegada [...] (F., ex-pescador, setembro de 2010).

O suporte de ajudantes de pesca (no Funil chamado de tarrafeiro) é muito comum em outros lugares também, e em grande parte dos casos os trabalhadores possuem algum vínculo de parentesco. Quando o vínculo do ajudante de pesca é de primeiro grau, esposa ou filhos, não costuma haver remuneração pelo trabalho. Quando não é parente, a remuneração geralmente ocorre pelo pagamento de um valor fixo, pelo pagamento de uma porcentagem do lucro obtido na venda do pescado ou, como no caso relatado, com a partilha de $50 \%$ do pescado para que, cada qual realize sua venda de maneira independente (VALENCIO, 2007).

O grande movimento, tanto de turistas quanto dos carros que transitavam pela região da Ponte do Funil, atraídos pelo comércio de peixes existentes no local, acabava possibilitando uma venda rápida do pescado. Pois, o fato do ambiente de captura e de residência estar próximo a uma infraestrutura viária de tráfego intenso favorecia a comercialização rápida da mercadoria, o que dispensava a necessidade de grandes infraestruturas de armazenamento do pescado.

Outro fator importante de ser ressaltado é que, em geral, a confecção e a manutenção dos petrechos de pesca, como as redes de espera e as tarrafas, eram feitas pelos próprios pescadores ou por seus familiares, o que demonstra uma autonomia na gestão das capacidades do trabalhador, e que, portanto, pode ser visto como um contraponto ao trabalho hierárquico e alienado que vigora na

\footnotetext{
${ }^{14}$ Importante ressaltar que em conversa com outros pescadores que trabalham a jusante do barramento, estes falam que realmente o Dourado acabou, ficaram todos "barrados" pra baixo da Usina e já a algum tempo não se houve mais falar de alguém que tenha conseguido pescar o Dourado a jusante da represa, o que era muito comum antigamente.
} 
sociedade mercantil (VALENCIO et al., 2006). Como nos informou um ex-pescador do Funil:

No rio a gente mesmo fabricava os equipamentos, rede, tarrafa, tudo a gente que fabricava, ao longo dos anos fomos aprendendo, a gente ia aprimorando os equipamentos de acordo com as condições entendeu, por exemplo, se o rio esta cheio é um tipo de equipamento, se as águas baixam é outro, a água mansa é um equipamento e na cachoeira é outro, então tudo isso ai, a gente vivia daquela atividade, tudo que a gente ganhava era daquilo, e quando acabou aquilo [a barragem que acabou com o rio] a gente ficou perdido, entendeu, totalmente perdido, e a usina, no começo até dava um empreguinho pra turma, e a turma na expectativa de trabalhar na Usina, o status de trabalhar na Usina, mas eu até falei, gente, isso ai não é pra nos, isso não tem futuro pra nos, a usina esta dando um "cala boca" ai pra gente, ai logo começou a dar cesta básica que foi uma coisa que eu fui contra também, porque tem que ensinar o povo a trabalhar, porque a hora que vocês cortar a cesta básica o povo vai passar fome, ai ficou, dão cesta básica até hoje, mas é muito cômodo pra eles dar cesta básica, porque é muito barato, então sempre que a FEAM cobra deles eles falam: 'não, estamos dando cesta básica', mas só que ninguém vive só de cesta básica não ué, e ficou ai, na pesca no lago a gente não se acertou até hoje, ninguém se acertou com a pesca no lago (A., ex-pescador, setembro de 2010).

É curioso observar essa passagem da autonomia para a dependência em relação ao consórcio empreendedor vivenciado pelos pescadores a partir da construção da barragem no Rio Grande, que provocou não só a perda dos espaços de pesca, mas também, a perda de todo um arcabouço cultural que é próprio do lugar. Como afirma Valencio (2007):

O rio, domesticado, são águas que revelam o destino trágico. Ao tomarem outras formas, constroem no interior dos mesmos novos conteúdos materiais e novas memórias para usos de novos homens. Portanto, é o rompimento da narrativa da tradição e do reconhecimento das vozes ancestrais que, mais do que transmutadas, são sufocadas pelo novo. A obstrução da memória social dá-se, dessa forma, pela perda da referência ecossistêmica com a qual aqueles saberes e fazeres tinha contato (VALENCIO, 2007, p. 39).

No item a seguir vamos discutir esses "novos homens" que a partir da extinção do antigo lugar de moradia e trabalho e das antigas técnicas de pesca, passaram a lidar com uma nova realidade a partir da implantação da piscicultura como forma de compensação à atividade antes praticada.

\subsection{A CRIAÇÃO EM TANQUES-REDE E A “EXTINÇÃO” DOS PESCADORES DO FUNIL}

A alternativa encontrada pelo consórcio para a atividade da pesca no lago que não havia atingido os resultados esperados foi a implantação da piscicultura através da criação de tilápias em tanques-rede. De acordo com Silva (2007), os tanques-rede são: "Estruturas flutuantes, confeccionados em variados formatos e 
tamanhos e diferentes materiais que permitem a livre circulação da água, trazendo oxigênio necessário aos peixes ali confinados e levando os resíduos e gases nocivos por eles produzidos" (SILVA, 2007, p. 04).

Segundo os pescadores, como forma de compensação, o consórcio doou toda a estrutura necessária para a realização da atividade, doou os tanques-rede, já haviam construído o Centro de Beneficiamento de Pescado (CBP) ${ }^{15}$, mas o grande problema enfrentado pelos pescadores, e apontado por todos os entrevistados, foi a falta de apoio técnico.

\begin{abstract}
A nossa maior dificuldade aqui em relação à criação de peixe tem sido um zootecnista pra fazer um levantamento da área pra ver o quê que está acontecendo com essa mortandade de peixe, a mudança de temperatura foi muito brusca então peixe de $500 \mathrm{~g}$ esta morrendo ai [...] o que está dificultando é isso, é o preço da ração que é muito caro e o fato da gente não ter acompanhamento, é muito difícil vir alguém aqui, pra um técnico chegar aqui e falar o quê que está acontecendo, mostrar o que está certo e o que está errado [...] (F., expescador, setembro de 2010).
\end{abstract}

O Consórcio ajuda muito nós com os tanques-rede, no que precisa eles ajudam, só que por enquanto ainda não está dando certo não, com relação à criação de peixe, porque nós coloca eles lá [os peixes nos tanques-rede] e eles morre tudo, a gente não tem conhecimento de criação [...] (J., ex-pescador, setembro de 2010).

Como podemos perceber, a criação de peixes em tanques-rede é uma atividade completamente estranha para os pescadores que não possuíam nenhum conhecimento prévio a respeito. Segundo Valencio (2007), não há, em termos ocupacionais, nenhuma correspondência entre o trabalho da pesca artesanal e o trabalho da aquicultura uma vez que, tomada uma coisa pela outra, há modificações sensíveis nas formas de interação homem-água-peixe dadas por uma ou outra atividade. De acordo com a autora:

O trabalho da aquicultura é de ordem substancialmente distinta da pesca artesanal. $O$ fato de ser um trabalho realizado no contato do trabalhador com a água e os peixes é um desvio das dessemelhanças que permanecem fundamentais. Para começar, a aquicultura é um processo alienador. Prescinde do conhecimento que o pescador artesanal tem do ambiente natural, bem como das habilidades técnicas corporais e de manejo dos instrumentos de trabalho a elas ajustadas. Outras são as habilidades requeridas pela aquicultura, as quais perdem a condição de ensino-aprendizagem no espaço comunitário e de difusão oral para dar espaço à orientação formal e hierarquizada do perito, oriunda da engenharia de pesca ou correlatas. Tais orientações sofrem mudanças a partir das circunstâncias que ocorrem na esfera de outras relações, científicas, tecnológicas ou político-empresariais e mercadológicas, que não são de domínio e, portanto, tornam-

\footnotetext{
${ }^{15} \mathrm{O}$ centro de beneficiamento de pescado tinha a finalidade apurar por processos técnicos o que se produz, no caso o peixe criado nos tanque-rede. Esse produto seria comercializado não somente In natura, mas beneficiado (filetagem, filé, etc.) para, assim, ser mais atrativo tornando-se de maior valor para o mercado. No entanto, esta pratica ainda não se concretizou no Funil.
} 
se incontroláveis para o grupo que as absorveria no trabalho direto nos tanques-rede (VALENCIO, 2007, p. 84).

Nesse sentido, a forma de aprendizagem para aquisição de conhecimentos necessários para a reprodução da atividade é completamente diferente. O que na pesca artesanal era passado de forma oral, pela tradição e através principalmente da família, na piscicultura a aprendizagem está relacionada a um conhecimento técnico-científico bastante específico e que na maioria das vezes se encontra fora do alcance dos pescadores, tornando-os dependentes. Ao perguntar a um entrevistado como ele adquiria o conhecimento necessário para lidar com os tanques-rede ele respondeu da seguinte maneira:

Assim, eu as vezes vejo um pouco em alguma revista, um curso que eles começaram a dar ai pela UFLA [Universidade Federal de Lavras] sabe, então você vai [...] esse zootecnista que vendeu esses últimos peixes pra nós ai, ele tava fornecendo um [...] diz ele que era uma vitamina né, então ele não fala qual é o segredo, não fala como é que é, né, [...] (F., ex-pescador, setembro de 2010).

Os pescadores, que antes fabricavam seus próprios instrumentos de trabalho e exerciam uma atividade autônoma, mesmo que ilegal, agora passaram a ser dependentes do conhecimento técnico que, como demonstra a fala anterior, Ihes é negado. Ficam na expectativa da boa vontade do consórcio em comprar alevinos, insumos, ração, ou seja, coisas que são extremamente caras para serem adquiridas pelos próprios pescadores.

Outro fator interessante de ser observado é a respeito da temporalidade que rege as duas atividades. No processo de produção de peixes, a temporalidade é subordinada a uma racionalidade industrial. O período de desenvolvimento dos peixes cultivados é dado pelo controle da natureza por vários meios técnicos, artificializando o processo no intuito de ir aproximando o tempo de trabalho do tempo de produção. Para isso, utiliza-se uma série de ciências especializadas para aumentar a eficiência da engorda, aumentar a resistência dos peixes às doenças, etc. Silva (2007) ressalta que:

O tempo de trabalho de tal empreendimento [piscicultura tanques-rede] é determinado, ou seja, os horários são estipulados a depender das tarefas efetuadas: alimentação com ração realizada inicialmente (alevinos) em curto espaço de tempo aumentando com o desenvolver do peixe, biometria ${ }^{16}$, limpeza quinzenal dos tanques e vigilância constante [...] Há, então, uma inversão do tempo de trabalho, ou seja, o que é conduzido pelo fator 'natureza', com a inserção dessa nova tecnologia é determinado pela tecnologia. Desta forma, o tempo determinado para cada tarefa é um dos fatores diferenciadores da atividade da pesca artesanal que se

\footnotetext{
${ }^{16}$ Conforme a autora: "A biometria é um termo técnico que representa a pesagem e medição de determinada amostra de peixe dos tanques-rede para se determinar o seu peso médio. Essa atividade é importante e dela depende toda a produção, pois, sua finalidade é de reajustar a quantidade de ração e sua densidade. A biometria dos peixes em tanques-rede deve ser feita no início da produção com os alevinos (filhotes de peixe) semanalmente, quando atingem certo peso a biometria é realizada quinzenalmente." (SILVA e SIQUEIRA, 1997, p. 85 apud SILVA, 2007).
} 
caracteriza por seu tempo de trabalho indeterminado (SILVA, 2007, p. 6).

Nessa nova temporalidade resta ao pescador o papel de cuidar de "gaiolas", os tanques-rede, preocupando-se com a temperatura da água, com a hora certa de dar ração aos alevinos e peixes maiores. Ao invés de redes e tarrafas agora o que ele tem é ração manufaturada e um barco para flutuar entre os tanques. O pescador artesanal se transforma em um proletário das águas e perde todos os referenciais econômicos, ambientais e sociais que construíram sua autonomia e requereram seu conhecimento, suas técnicas, tanto de captura quanto de criação dos seus meios de produção. Como aponta Valencio (2007), os pescadores experimentam uma temporalidade que é distinta da moderna, lidam em uma racionalidade onde a preservação da memória da paisagem e das práticas de manejo asseguram um sentido de pertencimento ao lugar e ao grupo. Essa temporalidade também perpassa a realização do trabalho, segundo a autora:

A arte da pesca não obedece aos tempos da racionalidade mercantil nem acomoda nos critérios de produtividade com os quais se the tentam impingir juízos. A visão de um pescador jogando tarrafa alude, geralmente, à estética do prazer, uma habilidade técnica delineada para provocar a ideia de domínio do corpo e domínio do rio, ambos inconstantes, porém, ajustáveis. A forma serpenteante do rio é o da ocultação, do mistério, a que o pescador afronta na canoa, fixo e móvel, isolado e exposto. O pescador tem na canoa a extensão do seu corpo para buscar um desconhecido a que a tarrafa surpreende. Retirem-se esses componentes imaginativos e, contra eles, coloquem-se motores e localizadores precisos de cardumes: tem-se a captura, esvai-se o prazer da pesca naquilo em que essa arte é um jogo, uma procura de algo em que só se sabe até certo ponto onde vai estar (VALENCIO, 2007, p. 38).

Agora imagine o que acontece quando não é apenas o aperfeiçoamento técnico dos meios de produção que ocorre, mas sim, a mudança na própria natureza da ocupação, com a extinção do trabalho de captura. O pescador deixa de ser um capturador ou "apanhador" de peixe e passa a ser um produtor de peixe e um "cuidador de gaiolas" (os tanques-rede), descaracterizando-se como pescadores artesanais e adotando uma nova identidade produtiva: a de piscicultor.

A mudança é significativa. Como comentou a socióloga da empresa de consultoria ambiental ${ }^{17}$ contratada pelo consórcio empreendedor para fazer 0 acompanhamento dos Programas de Reativação Econômica da Ponte do Funil, ao colocar a piscicultura como alternativa à pesca tradicionalmente praticada,

A maior dificuldade que se tem é que isso implica em uma mudança cultural, eles [os pescadores] têm uma cultura que eles pescam a hora que querem, do jeito deles, na hora que eles acham certo, e quando você muda para uma produção cotidiana, todo dia, quando muda o modo de produção e eles passam a ter que estar lá de tal a tal hora, isso eles não conseguem, não mudam, é difícil (G., socióloga da Práxis, maio de 2010).

\footnotetext{
${ }^{17}$ Empresa Práxis Projetos e Consultoria, sede em Belo Horizonte.
} 
Como se pode perceber a partir da fala da técnica, o que ocorreu foi um processo de mudança cultural, ou seja, não é apenas uma mudança no modo de produção, mas uma mudança de valores e perspectivas que perpassa inclusive a questão da identidade destes pescadores. Valencio (2007), reportando à análise de Diegues (1998), afirma que a construção social da identidade do pescador artesanal passa fundamentalmente por três aspectos principais: (I) ocorre pela alteridade, pelas formas como reconhece o outro; (II) pelos rituais de reafirmação dos significados e sentidos partilhados por seu coletivo; e por fim, (III) pela afirmação do sentido de pertencimento ao lugar.

O outro é aquele com quem entra em conflito pelo uso da água e pela exploração dos recursos pesqueiros, como é o caso das concessionárias de energia, os pescadores amadores, etc. Os sentidos partilhados pelo grupo também é definidor de sua identidade, principalmente aqueles relacionados a certas visões do peixe, do seu comportamento e do ambiente aquático. Mas uma questão central desse processo é a territorialidade. Como explica a autora:

Por fim, a identidade repousa na afirmação da sua territorialidade, do seu direito de estar no lugar e dele retirar seu provimento, de entender que sua sobrevivência reside na fruição multidimensional daquele lugar. O conjunto de práticas sociais relacionadas ao trabalho está geograficamente referido, isto é, as referências territoriais da pesca compreendem tanto as particularidades ambientais de dado trecho do rio onde se quer atuar quanto os tipos de acordo que se faz para a exploração coletiva do mesmo (VALENCIO, 2007, p. 30).

Se a construção da identidade de pescador passa por essas dimensões, como ficaria a identidade de um grupo que teve seu lugar submerso pela barragem de uma usina hidrelétrica, ou seja, que perdeu a sua territorialidade, e que mudou de atividade? Com certeza este grupo terá sua identidade abalada. Essa questão da territorialidade não está relacionada exclusivamente ao espaço do trabalho, mas também, ao espaço da casa, da sua moradia, sua relação com os vizinhos, etc.

$\mathrm{Na}$ Comunidade do Funil, muitas pessoas sofreram com o processo de mudança, principalmente os mais velhos. Na fala dos pescadores atingidos, ao serem perguntados sobre como foi a chegada ao novo local, essa dimensão é explicitada:

[...] cada um foi criado no seu habitat natural, é a mesma coisa que você tirar uma onça do pantanal e colocar ela dentro de São Paulo, ela vai ficar o quê? Perdida, ela não sabe nada, é a mesma coisa com nós, nós ficamos totalmente perdido, até nós achar o caminho, até nós consegui pegar um ritmo de vida que nunca mais vai ser o mesmo, pelo menos pra gente ir sobrevivendo, levou muito tempo. Muitos até adoeceram (...) teve até infarto, porque não acreditava, (...) eu acho assim, que em respeito aos mais velhos deveria ter um psicólogo pra acompanhar, porque esse pessoal tem tudo na mão, tem dinheiro, as pessoas mais velhas sofrem mais, você tirar um menino de 2 anos e outro de 100 anos, a de 100 anos sofre mais, nessa parte eu acho [...] (G., ex-pescador, setembro de 2010). 
$\mathrm{Na}$ chegada aqui, só dos antigos morreram três, porque não adaptou aqui, pergunta eles ai, morreu porque não adaptou; é igual eu falei com você, essa bagunçaiada, brigaiada, começou o povo vindo pra cá, o povo que gosta da beira d'água, dos bar, esses trem, ai bagunçou tudo, ai já era. La tinha os bar na época, tinha mas era um ou outro, não tinha tanta bagunça como tem hoje, hoje ficou um em cima do outro, concentrou muito num lugar só (J.,ex-pescador, setembro de 2010).

[...] tem um que morreu, a turma fala que ele morreu de desgosto, porque ele gostava muito da pesca e tudo, ai chegou aqui ele se entregou na bebida, mais é difícil você provar isso aí né [...] (A., ex-pescador, setembro de 2010).

A dificuldade de adaptação ao novo lugar foi muito sentida pelas pessoas mais velhas, que tinham um vínculo e um sentimento de pertencimento ao antigo lugar de moradia muito forte ${ }^{18}$. Acostumados a viverem no rio e do rio, lugar onde os sentidos eram partilhados com o grupo, o enchimento do lago da usina acaba submergindo a identidade daqueles que no rio se inspiravam. Por outro lado, os mais jovens, apesar de também terem sofrido com o processo de mudança, sentiram uma maior facilidade de adaptação à nova realidade. Como nos informou um ex-pescador, mais jovem, e que é membro da COOPERFUNIL:

Os primeiros meses eu estranhei, eu fui pra casa do meu pai e lá tinha uns vizinhos, que agora nem moram lá mais, mas que era meio complicado, era muito som alto, muita criança, muita gritaria, jogavam bola na rua e caia toda hora dentro de casa, foi até meio estranho, mas ai depois devagar foi adaptando, hoje eu acostumei tanto que eu acho que se fosse viver igual nós vivíamos lá eu ia estranhar (N., ex-pescador, setembro de 2010).

Nesse sentido, o que pudemos perceber a partir da pesquisa realizada foi que, com o passar do tempo, os mais jovens foram se adaptando ao novo estilo de vida que Ihes foi imposto. Com a transferência do local de moradia os pescadores passaram a ter maior contato com o meio urbano e, expostos cada vez mais ao conjunto de valores subjacentes à vida na cidade e trabalhando numa nova função jamais imaginada anteriormente, os mesmos foram aos poucos perdendo a sua identidade de pescador.

\section{CONCLUSÕES}

Como foi analisado ao longo deste artigo, os pescadores que tinham no Rio Grande sua principal fonte de retirada de recursos, têm seus meios de vida alterados drasticamente com a construção da Usina Hidrelétrica do Funil. Ou seja, ao perderem o acesso ao rio e, consequentemente à pesca, muitos desses pescadores deixaram de exercer a pesca artesanal e foram buscar outras formas de obtenção de renda. A opção pela piscicultura como alternativa, uma atividade até então desconhecida e completamente diferente do modo tradicional como a pesca vinha

\footnotetext{
${ }^{18}$ Para uma análise sobre os processos de deslocamento compulsório e reassentamento de atingidos por usinas hidrelétricas, com base no estudo da hidrelétrica de Candonga, na Zona da Mata mineira, ver Penido (2007).
} 
sendo realizada naquela região, acabou provocando, inclusive, uma alteração na própria identidade destes pescadores.

Se levarmos em consideração o fato de que o primeiro aspecto da construção social da identidade do pescador é o reconhecimento do outro, e este sendo aquele com quem se está em conflito pelo uso da água, como é o caso das concessionárias de energia hidrelétrica, o que poderia ocorrer quando os próprios pescadores se veem trabalhando para este outro? O que observamos no caso dos pescadores do Funil foi a dissolução da identidade destes pescadores que agora passam a ser identificados com o próprio outro que os "definiam" por oposição. Além disso, a utilização dos conhecimentos e dos saberes destes pescadores no trabalho para as hidrelétricas acaba reforçando a hegemonia de uma visão utilitarista das águas cuja tônica é priorizar os atendimentos das finalidades modernas.

Por fim, é curioso atentar para uma contradição vivida pelos ex-pescadores do Funil, ou seja, para o fato de que antes da construção da usina hidrelétrica estes atingidos, apesar de exercerem uma prática ilegal, eram pescadores. Com o enchimento do lago da usina, eles passam para a legalidade, adquirem a carteira de pescador profissional, mas deixam de ser pescadores e passam a ser produtores de peixe. Este fato fez com que passassem a trabalhar de forma a reafirmar uma visão hegemônica sobre o espaço das águas em que se privilegia uma racionalidade econômica, instrumental, que está colocando em risco de extinção uma categoria ocupacional e um meio de vida específico, qual seja o do próprio pescador artesanal.

\section{REFERÊNCIAS}

BRASIL. Lei $\mathrm{n}^{\circ}$ 11.959, de 29 de junho de 2009. Dispõe sobre a Política Nacional de desenvolvimento sustentável da aquicultura e pesca. Disponível em: <http://www.mpa.gov.br/\#legislacao/Leis/leis2009>. Acesso em: 05 out. 2010.

DIEGUES, A. C. S. Pescadores, camponeses e trabalhadores do mar. São Paulo: Ed. Ática, 1983.

DIEGUES, A. C. S. Povos e mares: leituras em sócio-antropologia marítima. São Paulo: NAPAUB, 1995.

ECODINÂMICA CONSULTORES ASSOCIADOS Ltda. Relatório de avaliação de desempenho ambiental (RADA) do reservatório da UHE Funil - Consórcio AHE Funil. Belo Horizonte, 2006.

ELLIS, F. Rural Livelihoods and diversity in developing countries. Oxford: Oxford University Press, 2000.

FELDMAN- BIANCO (org). Antropologia das sociedades contemporâneas: Método, São Paulo: Global, 1987.

GOMES, R. Análise e Interpretação de Dados de Pesquisa Qualitativa. In: MINAYO, Maria Cecília de Sousa (org). Pesquisa social: teoria, método e criatividade. Petrópolis: Vozes, 2007, p. 79-108.

HENBICK, P. et al. Livelihoods and landscapes: The people of Guquka and Koloni and thier resources. (org.) Hebinck, Paul and Lent, C. Peter.Leinden. Brill, Leidein, Boston, 2007. 
LEFF, E. Saber ambiental: Sustentabilidade, racionalidade, complexidade, poder. Petrópolis: Editora Vozes, 2001.

MENDONÇA, S. A. T. Turismo e pesca profissional artesanal: impactos socioambientais no Alto-Médio São Francisco. Teoria e Pesquisa: Revista de Ciências Sociais. São Carlos, v. 1, n. 44-45, Jan./Jul.2004. Disponível em: $<$ http://www.teoriaepesquisa.ufscar.br/index.php/tp/article/viewFile/80/70 >. Acesso em: 05 out. 2010.

PASQUOTO, V. F.; MIGUEL, L. A. Pesca artesanal e enfoque sistêmico: uma atualização necessária. In: ENCONTRO DA SOCIEDADE BRASILEIRA DE SISTEMAS DE PRODUÇÃO, 6. 2004. Aracaju. Anais... Aracaju. 2004. 12p.

PEREIRA, M. P.; BOTELHO, M. I. V. As interferências da legislação ambiental sobre os meios de vida das comunidades rurais e o papel da Extensão Rural. Extensão Rural, Santa Maria, v. 22, n. 2, 2015.

SILVA, P. S. De pescador a piscicultor: as transformações do processo produtivo dos ribeirinhos no baixo São Francisco. In: REUNIÃO EQUATORIAL DE ANTROPOLOGIA - REA, 2007. Aracaju. América Equatorial - Cultura na Contemporaneidade, 2007.

VALENCIO, N. F. L. S.; MENDONÇA, S. A. T.; MARTINS, R. C. Da Tarrafa ao Tanque-rede: o Processo Político-institucional de Extinção de uma Categoria de Trabalhadores das Águas. In: VALENCIO, N. F. L. S.; MARTINS, R. C. (Orgs.) Uso e gestão dos recursos hídricos no Brasil: desafios teóricos e políticoinstitucionais. Volume II - São Carlos: RIMA, 2003. p. 271 - 293.

VALENCIO, N. F. L. S. et al. Condições de Vida e Trabalho do Pescador Profissional da Bacia do Alto/Médio São Francisco. In: VALENCIO, N. F. L. S.; MARTINS, R. C.; LEME, A. A. (Orgs.). Uso e gestão dos recursos hídricos no Brasil: desafios à cidadania. 2 ed. São Carlos: RIMA, 2006. p.187 - 204.

VALENCIO, N. F. L. S. A Pesca Artesanal como identidade: mercantilização e dissolução de um modo de vida rural. In: CONGRESSO LATINO AMERICANO DE SOCIOLOGÍA RURAL, 7., 2006. Quito. Anais... Quito: ALASRU/ FLACSO, 2006. Disponível em: <http://www.alasru.org/cdalasru2006/27\%20GT\%20Norma\%20Felicidade\%20L\%20 S\%20Valencio.pdf >. Acesso em: 05 out. 2010.

VALENCIO, N. F. L. S. Pescadores do Rio São Francisco: a produção social da inexistência. São Carlos: RIMA, 2007.

VAN VELSEN, J. A Análise Situacional e o método de estudo de caso detalhado. In: Feldman-Bianco (org). Antropologia das sociedades contemporâneas: Método, São Paulo: Global, 1987.

VENTURATO, R. D. Desafios do modo de vida da pesca artesanal em água doce num contexto socioambiental adverso: uma análise sociológica do caso do bairro rural do Tanquã, Piracicaba/ SP. 2008. 144f. Dissertação. Mestrado em Agroecologia e Desenvolvimento Rural. Centro de Ciências Agrárias. Universidade Federal de São Carlos. Araras. 2008. 